\title{
Perioperative Dexmedetomidine Fails to Improve Postoperative Analgesic Consumption and Postoperative Recovery in Patients Undergoing Lateral Thoracotomy for Thoracic Esophageal Cancer: A Randomized, Double-Blind, Placebo-Controlled Trial
}

\author{
Yu Mao, ${ }^{1,2}$ Xuemei Sun, ${ }^{1}$ Li Si, $^{3}$ Lijian Chen, ${ }^{1}$ Xuesheng Liu, ${ }^{1}$ Zhi Zhang, ${ }^{2}$ and Erwei Gu $\mathbb{B D}^{1}$ \\ ${ }^{1}$ Department of Anesthesiology, First Affiliated Hospital of Anhui Medical University, Jixi Road 218, Hefei City, \\ Anhui Province, China \\ ${ }^{2}$ School of Life Sciences, University of Science and Technology of China, Huangshan Road 443, Hefei City, Anhui Province, China \\ ${ }^{3}$ Department of Laboratory, First Affiliated Hospital of Anhui Medical University, Jixi Road 218, Hefei City, \\ Anhui Province, China \\ Correspondence should be addressed to Erwei Gu; ay_guew_mz@163.com
}

Received 28 December 2019; Revised 9 March 2020; Accepted 18 March 2020; Published 7 May 2020

Guest Editor: Laiche Djouhri

Copyright ( 2020 Yu Mao et al. This is an open access article distributed under the Creative Commons Attribution License, which permits unrestricted use, distribution, and reproduction in any medium, provided the original work is properly cited.

\begin{abstract}
Objectives. Dexmedetomidine is widely used as an adjunct to general anesthesia. In this study, we evaluated the effects of perioperative dexmedetomidine infusion on postoperative analgesia in patients undergoing lateral thoracotomy for thoracic esophageal cancer. Methods. A total of 62 patients undergoing lateral thoracotomy for thoracic esophageal cancer were randomized to receive adjuvant therapy with either dexmedetomidine $(0.5 \mu \mathrm{g} / \mathrm{kg}$ intravenous bolus injection for $10 \mathrm{~min}$ before induction of anesthesia, followed by continuous infusion of $0.2-0.4 \mu \mathrm{g} / \mathrm{kg} / \mathrm{h}$ until the end of surgery, and $0.06 \mu \mathrm{g} / \mathrm{kg} / \mathrm{h}$ for $5 \mathrm{days}$ after surgery) or equal volumes of saline. Acute postoperative pain was treated with patient-controlled intravenous sufentanil and flurbiprofen axetil. The primary outcomes of this study were the numbers of analgesic requirements in the first postoperative $72 \mathrm{~h}$. Results. Perioperative dexmedetomidine did not decrease the numbers of analgesic requirements in the first postoperative $72 \mathrm{~h}$ (dexmedetomidine group: $12.14 \pm 4.76$, saline group: $10.89 \pm 5.66 ; p=0.367$ ). Likewise, the groups did not differ with respect to total postoperative analgesic requirements, postoperative pain, perioperative inflammation, blood cell count, incidence of adverse events, surgical recovery (assessed at postoperative days 2 and 5 using the surgical recovery scale), length of hospital stay, hospital cost, incidence of chronic pain, or quality of life. Notably, dexmedetomidine had beneficial effects on decreasing intraoperative opioid consumption and improving postoperative sleep quality. Discussion. Perioperative dexmedetomidine has limited analgesic benefits in lateral thoracotomy for esophageal cancer when added to an opioid-based multimodal anesthetic regimen but can reduce opioid consumption.
\end{abstract}

\section{Introduction}

Postoperative pain management after thoracic surgery remains a challenge [1-4]. The underlying mechanisms of acute postoperative pain in thoracotomy are likely multifactorial and are mainly due to direct surgical trauma to ribs, costovertebral joints, intercostal nerves, and/or pleural irritation from chest tubes [3]. Adequate postoperative analgesia is imperative for reducing morbidity in postthoracotomy patients, improving functional outcomes, enhancing short-time recovery, and preventing the chronification of acute pain [5-7].

Opioids are still considered mainstream for postoperative pain control but cause adverse effects including sedation, pulmonary depression, constipation, urinary retention, pruritus, hyperalgesia, postoperative nausea, and vomiting $[8,9]$. These adverse effects are not only associated with perioperative morbidity and mortality but can also delay 
hospital discharge and increase hospital costs. Therefore, modern analgesic strategies aiming at reducing opioid-induced side effects represent a multimodal approach $[2,4,10]$.

Dexmedetomidine is a highly selective $\alpha 2$-adrenergic receptor agonist that has sedative and analgesic-sparing effects $[11,12]$, perioperative sympatholysis [13], and reduced postoperative delirium and agitation [14-16]. In patients undergoing lateral thoracotomy for pulmonary resection, perioperative administration of dexmedetomidine for postoperative pain control decreases opioid consumption, provides effective postoperative analgesia, and improves patient satisfaction. However, data on the efficacy and safety of dexmedetomidine in lateral thoracotomy for thoracic esophageal carcinoma are lacking $[17,18]$.

We hypothesized that, in patients undergoing lateral thoracotomy for thoracic esophageal cancer, perioperative dexmedetomidine infusion would reduce opioid requirements and provide postoperative pain relief for patients who are not available for neural blockade. In the present study, we assessed peripheral cell counts, the pattern of inflammatory responses, sleep quality, surgical recovery, the incidence of chronic pain, and quality of life after surgery.

\section{Methods}

2.1. Study Design and Population. A total of 62 patients undergoing lateral thoracotomy for thoracic esophageal cancer were enrolled in this prospective, double-blinded randomized, placebo-controlled trial.

The study protocol was approved by the Human Research Ethics Committee of Anhui Medical University (20180224) and was registered in the Chinese Clinical Trial Register (No. ChiCTR 1800015054, Principal Investigator: $\mathrm{Yu}$ Mao, Date of Registration: March 5, 2018). Patients were enrolled between March and July of 2018. Inclusion criteria consisted of age being 18-75 years and an American Society of Anesthesiologists (ASA) physical status of I-III. The exclusion criteria included the following: hypersensitivity to dexmedetomidine, conduction abnormalities other than atrioventricular block, bradycardia, rate-controlled atrial fibrillation, abnormal ventricular ejection (defined as left ventricular ejection fraction $<50 \%$ ), liver impairment (defined as total serum bilirubin $\geq 34.2 \mu \mathrm{M}$ ), renal disease (defined as glomerular filtration rate $\leq 60 \mathrm{~mL} / \mathrm{min} / 1.73 \mathrm{~m}^{2}$ ), serious central nervous system pathology, chronic pain, psychiatric disorder, epilepsy, communication disability, or psychological/physical dependence on opioids (e.g., transdermal fentanyl or morphine). Informed consent was obtained from patients prior to initiation of the study. Demographic and other confounding variables including age, gender, ASA status, height, weight, surgical recovery scale, and sleep quality were collected in ward the day before surgery. Patients were randomized to either a saline or dexmedetomidine group using a computer-generated random sequence of numbers with a $1: 1$ allocation ratio. Allocation concealment was achieved by concealing assignments in sequentially numbered, opaque, sealed envelopes, which were opened after the arrival of the patient in the operating room. Blinding of research personnel and the staff involved in the study was maintained throughout the study and during all of the postoperative follow-ups.

2.2. Study Intervention. Patients in the dexmedetomidine group were intravenously infused with dexmedetomidine at a loading dose of $0.5 \mu \mathrm{g} / \mathrm{kg}$ for $10 \mathrm{~min}$ before induction of anesthesia, followed by continuous infusion of $0.2-0.4 \mu \mathrm{g} /$ $\mathrm{kg} / \mathrm{h}$ until the end of surgery, which was continued at $0.06 \mu \mathrm{g} / \mathrm{kg} / \mathrm{h}$ for 5 days after surgery [12, 17-19]. Patients in the saline group were administered equivalent volumes of saline via the identical scheme as that for the dexmedetomidine group. The study drugs were prepared by an anesthetist, who was not a member of the research team and did not participate in administering the anesthesia or follow-up of the study participants. The study medication was prepared in a $20 \mathrm{~mL}$ syringe (for continuous infusion during anesthesia) and a $250 \mathrm{~mL}$ pump (for the postoperative continuous infusion at $2 \mathrm{~mL} / \mathrm{h}$ ). The $20 \mathrm{~mL}$ syringe contained $10 \mu \mathrm{g} / \mathrm{mL}$ of dexmedetomidine solution or an equal volume of $0.9 \%$ saline. The $250 \mathrm{~mL}$ pump contained either $7.2 \mathrm{mg} / \mathrm{kg}$ of dexmedetomidine $(0.06 \mu \mathrm{g} / \mathrm{kg} / \mathrm{h})$ or a $0.9 \%$ saline solution.

2.3. Anesthesia Protocol. General anesthesia was induced with midazolam $(0.05 \mathrm{mg} / \mathrm{kg})$, sufentanil $(0.5 \mu \mathrm{g} / \mathrm{kg})$, and a target-controlled infusion (TCI) of propofol using the Marsh model [20, 21] (Graseby 3500 Anesthesia Pump; Graseby Medical Ltd., Lower Pemberton, UK). The initial target effective concentration was $1.0 \mu \mathrm{g} / \mathrm{mL}$, which gradually increased by $0.3 \mu \mathrm{g} / \mathrm{mL}$ until the bispectral index (BIS; Vista; Aspect Medical Systems Inc., Norwood, Norfolk County, MA, USA) value was below 60 . Rocuronium $(0.9 \mathrm{mg} / \mathrm{kg})$ was administered for double-lumen endotracheal tube placement. Anesthesia was maintained with continuous TCI of propofol and remifentanil after intubation, and one-lung ventilation was applied during surgery. The rate of propofol was titrated to maintain a BIS value between 40 and 60, and the doses of intraoperative remifentanil, rocuronium, and sufentanil were titrated according to the discretion of the anesthetist. After completion of the surgical procedure, patients were admitted to the postanesthesia care unit (PACU) and were extubated. An injection of flurbiprofen axetil $(1 \mathrm{mg} / \mathrm{kg})$ was provided prior to surgery, whereas sufentanil $(0.1-0.2 \mu \mathrm{g} / \mathrm{kg})$ and flurbiprofen axetil $(1 \mathrm{mg} / \mathrm{kg})$ were administered at the end of surgery, followed by patientcontrolled intravenous (i.v.) analgesia (PCIA) of a mixture of sufentanil and flurbiprofen axetil in $250 \mathrm{~mL}$ at a concentration of $0.03 \mu \mathrm{g} / \mathrm{kg} / \mathrm{mL}$ and $1 \mathrm{mg} / \mathrm{mL}$, respectively. The PCIA pump included a background infusion of $2 \mathrm{~mL} / \mathrm{h}$ without a loading dose and a demand dose of $2 \mathrm{~mL} / \mathrm{h}$ with a lockout interval of $15 \mathrm{~min}$. An additional bolus of PCIA was given by the nurses in the PACU if the visual analog scale (VAS) for pain exceeded 3. Prophylaxis against postoperative nausea and vomiting (PONV) was performed with dexamethasone $(0.2 \mathrm{mg} / \mathrm{kg}$ [ $\mathrm{max}, 8 \mathrm{mg}])$ before the induction of anesthesia and azasetron $(0.2 \mathrm{mg} / \mathrm{kg}$ [max, $10 \mathrm{mg}])$ at the end of surgery. Pantoprazole ( $40 \mathrm{mg}$, i.v.) was 
administered to treat PONV if the VAS for nausea and vomiting exceeded 3.

2.4. Study Outcomes. The primary outcome was the effective pressing numbers of PCIA-boli during the first postoperative $72 \mathrm{~h}$. Secondary endpoints included the following: (1) severity of postoperative pain at rest and movement, as evaluated with the VAS $(0=$ no pain, $10=$ worst imaginable pain) once daily on postoperative days (PODs) 1, 2, and 5; (2) incidence of PONV during the first 5 PODs; (3) sleep quality, as assessed using St. Mary's Hospital Sleep Questionnaire [22], once daily on PODs 2 and 5 including sleep quality $(1=$ worst possible sleep, $6=$ best possible sleep), being clear-headed after getting up in the morning $(1=$ most drowsy, $6=$ best alertness), and sleep satisfaction $(1=$ most unsatisfied, 5 = most satisfied); (4) inflammatory markers, as examined by the serum concentrations of interleukin- 6 (IL6), IL-10, and C-reactive protein (CRP) and measured at four distinct time points: T0, prior to induction of anesthesia (baseline); T1, at the end of the operation; T2, the morning of the second POD; and T3, the morning of POD 5; (5) full blood count, serum glucose, and immune cell subset analysis, as measured at three time points: T0, prior to induction of anesthesia (baseline); T1, the morning of POD 2; and T2, the morning of POD 5; (6) short-term recovery (defined as the time to awakening, extubation, first movement of leaving the bed, first intestinal aerofluxus, hospitalization cost, length of PACU stay, hospital stay, and postoperative hospital stay); (7) surgical recovery scale (SRS) [23], as evaluated 1 day prior to surgery and on PODs 2 and 5 (each item response was scored in order from " 1 " to " 5 " or " 6 ," depending on the number of possible responses for each item); (8) incidence of chronic postsurgical pain at 3 months after surgery; and (9) quality of life as measured with the Short Form 8 (SF-8) health survey [24] (each item response was scored in order from " 1 " to " 5 " or " 6 ," depending on the number of possible responses for each item) at 1 day prior to surgery and at 1 and 3 months after surgery (administered by phone) [25].

2.5. Safety. The study drug was administered to patients with close hemodynamic monitoring in a completely equipped operative room and ward. This facilitated immediate detection and management of adverse events including bradycardia, tachycardia, hypotension, and hypertension $[11,16]$. Bradycardia was defined as a heart rate $<55 \mathrm{bpm}$ or $a>20 \%$ decrease from baseline (in the case of a prestudy drug infusion value $<69 \mathrm{bpm}$ ). Tachycardia was defined as heart rate $>100 \mathrm{bpm}$ or $a>20 \%$ increase from baseline (in the case of a prestudy drug infusion value $>83 \mathrm{bpm}$ ). Hypotension was characterized as mean blood pressure $<60 \mathrm{~mm} \mathrm{Hg}$ or $a>20 \%$ decrease from baseline (in the case of a prestudy drug infusion value $<75 \mathrm{mmHg}$ ). Hypertension was characterized as systolic blood pressure $>160 \mathrm{bpm}$ or $a>20 \%$ increase from baseline (in the case of a prestudy drug infusion value $>133 \mathrm{mmHg}$ ). Administration of study medication was immediately adjusted or stopped when participants showed dexmedetomidine-associated adverse reactions.

2.6. Blood Sample Acquisition and Laboratory Methods. In patients from both groups, $4 \mathrm{~mL}$ of venous blood samples in EDTA was obtained before the induction of anesthesia (T0), at the end of surgery (T1), on POD 2 (T2), and on POD 5 (T3). A full blood count of a $2 \mathrm{~mL}$ blood aliquot from three time points (T0, T2, and T3) was analyzed using the hematology analyzer, Sysmex XE-2100 (Sysmex, Kobe, Japan). A volume of $2 \mathrm{~mL}$ of blood samples from four time points (T0, T1, T2, and T3) was immediately centrifuged at $2,500 \mathrm{rpm}$ for $15 \mathrm{~min}$ and was then stored at $-80^{\circ} \mathrm{C}$ until subsequent analysis of IL-6, IL-10, and CRP concentrations. Inflammatory markers were measured using commercial enzyme-linked immunosorbent assay (ELISA) kits (Human CRP/IL-6/IL-10 Quantikine ELISA Kits; R\&D Systems, Inc., Minneapolis, MN, USA). CRP was expressed as $\mu \mathrm{g} / \mathrm{mL}$, whereas IL- 6 and IL-10 were expressed as $\mathrm{pg} / \mathrm{mL}$. The coefficient of variation of the assay for the entire sample batch was $10.8 \%$.

2.7. Statistical Analysis. The sample size calculation, based on our pilot data and previous study [26] of differences in effective pressing numbers of PCIA during the first postoperative $72 \mathrm{~h}$, indicated that a total of 55 patients were needed to provide a power of 0.8 to detect a clinically significant difference between a group mean effective pressing numbers of 12 with a pooled standard deviation (SD) of 5.6 at a level of 0.05 ; this equates to a $33.3 \%$ difference between means. Thus, a total of 62 patients ( 31 in each group) were recruited to account for potential dropouts. All statistical analyses were performed using SPSS version 22 for Windows (SPSS Inc., Chicago, IL, USA) and GraphPad Prism version 5 (GraphPad Software, Inc., La Jolla, CA, USA). Additionally, a per-protocol analysis, excluding patients lost to follow-up, was performed. Categorical data were analyzed using the $\chi$ [2] test, and comparison of proportions was analyzed using Fisher's exact test. A Mann-Whitney $U$ test was performed to analyze the pressing numbers of PCIA (primary outcome) and other quantitative parameters between the two groups. $p$ values $<0.05$ were considered statistically significant.

\section{Results}

The modified Consolidated Standards of Reporting Trials diagram represents the recruited patients (Figure 1) [27, 28]. A total of 68 patients were screened for lateral thoracotomy, among which 62 patients were randomized to treatment with dexmedetomidine $(n=31)$ or saline $(n=31)$. The inhospital per-protocol population included 58 patients, as one patient in the saline group or dexmedetomidine group died of anastomotic leakage, one patient in the saline group was lost to follow-up, and one patient in the dexmedetomidine group was excluded due to hemodynamic instability. The per-protocol population at 3 months after surgery was 56 patients because one patient in the saline group was lost to 


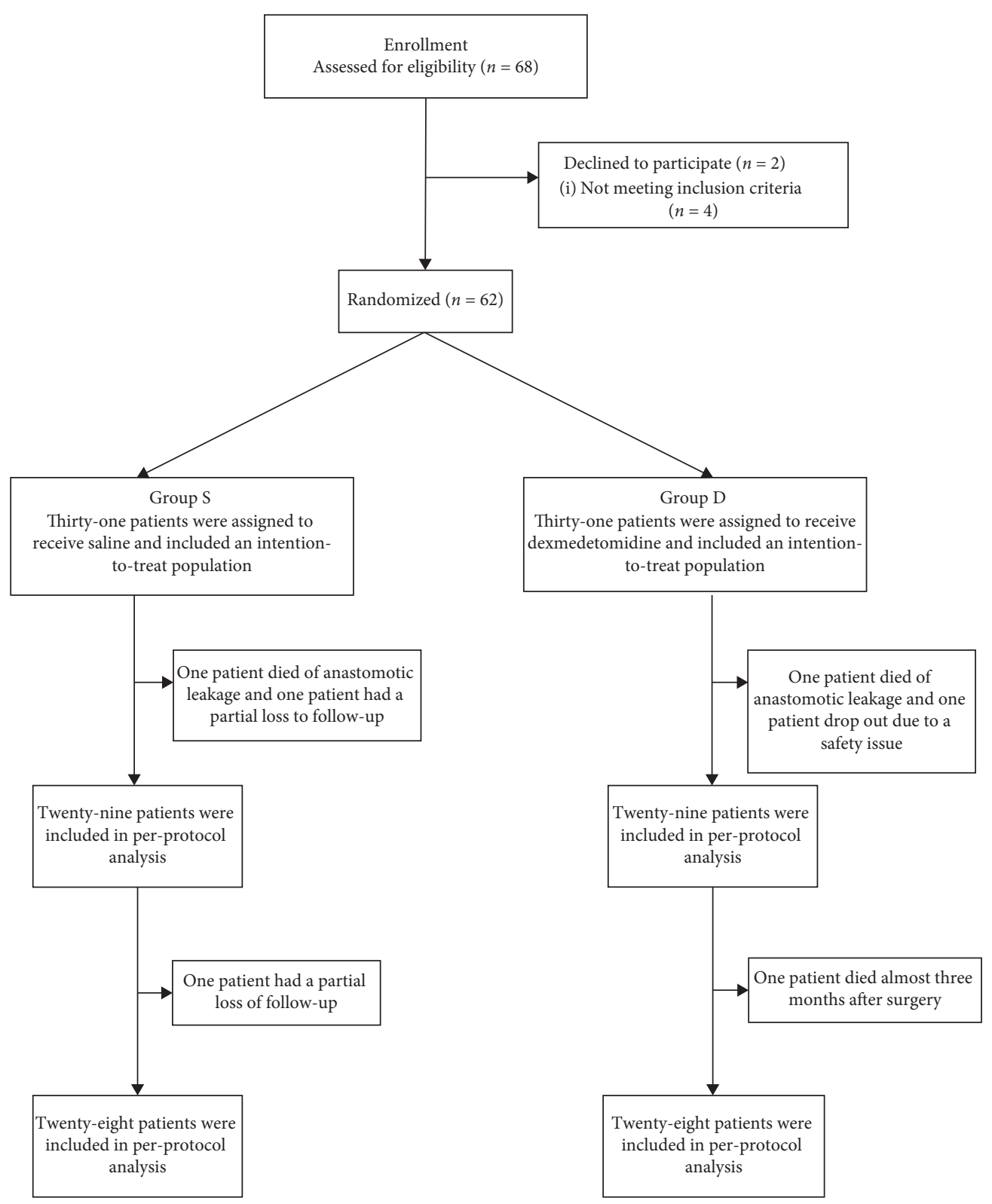

FIgURe 1: Flowchart.

follow-up and one patient in the dexmedetomidine group died at almost 3 months after surgery, precluding any assessment of quality of life.

3.1. Preoperative Assessment and Intraoperative Data. There was no difference between the two groups with respect to patient characteristics (Table 1). Surgery, anesthesia, and PACU-related data were comparable between the two groups, with the exception of sufentanil and remifentanil consumption, which was significantly higher in the saline group than in the dexmedetomidine group $(p=0.008$ and $p=0.015$, respectively; Table 2 ).

3.2. Primary Outcomes. Effective pressing numbers of PCIA-boli during the first postoperative $72 \mathrm{~h}$ were not significantly different between the saline and dexmedetomidine groups $(12.14 \pm 4.76$ versus $10.89 \pm 5.66, p=0.367$; Table 2).

3.3. Secondary Outcomes. The two groups did not differ with respect to the VAS for pain at rest or movement at any time point (Table 2). The two groups also did not differ regarding the total numbers of PCIA-boli delivered by a pump during the first five PODs (Table 2). Sleep quality on PODs 2 and 5 and a clear-headed feeling after waking up on POD 5 were better in the dexmedetomidine group than in the saline group. Sleep satisfaction on PODs 2 and 5, the PONV incidence during the first five PODs, time to the first out-ofbed activity, time to removal of the chest drainage tube, time to the first intestinal aerofluxus, time until discharge, time of postoperative stay, and hospital cost were not significantly 
TABle 1: Patient characteristics.

\begin{tabular}{|c|c|c|c|c|}
\hline & & Saline $(n=29)$ & Dexmedetomidine $(n=29)$ & $p$ value \\
\hline Age & Years & $63.48 \pm 8.44$ & $65.21 \pm 7.31$ & 0.409 \\
\hline Gender & $n(\%)$ & & & 0.738 \\
\hline Male & & $24(82.76)$ & $23(79.31)$ & \\
\hline Female & & $5(17.24)$ & $6(20.69)$ & \\
\hline Height & $\mathrm{Cm}$ & $166.10 \pm 7.00$ & $165.76 \pm 7.32$ & 0.855 \\
\hline Weight & $\mathrm{Kg}$ & $60.45 \pm 14.88$ & $56.59 \pm 11.18$ & 0.268 \\
\hline BMI & $\mathrm{kg} / \mathrm{m}^{2}$ & $21.09 \pm 5.13$ & $20.47 \pm 2.95$ & 0.196 \\
\hline ASA & $n(\%)$ & & & 0.788 \\
\hline I & & $12(41.38)$ & $11(37.93)$ & \\
\hline II & & $17(58.62)$ & $18(62.07)$ & \\
\hline Surgical recovery scale & & $61.2 \pm 11.39$ & $62.3 \pm 12.01$ & 0.729 \\
\hline Sleep quality & & $5.00[4.00-5.00]$ & $5.00[5.00-5.00]$ & 0.087 \\
\hline Clear-headed after getting up & & $5.00[4.00-5.00]$ & $5.00[4.00-5.00]$ & 0.273 \\
\hline Sleep satisfaction & & $4.00[4.00-4.00]$ & $4.00[3.00-4.00]$ & 0.192 \\
\hline
\end{tabular}

Data are presented as absolute numbers $(n)$, percentages of the total population $(N)$, and the mean \pm standard error or median (interquartile range), as appropriate.

different between the two groups (Table 2). Likewise, the SRS survey did not differ between the two groups on PODs 2 and 5 (Table 2). In addition, the SF-8 generic health survey was comparable between the two groups at both 1 and 3 months after surgery, and the incidence of chronic postsurgical pain did not differ between the two groups (Table 3 ).

3.4. Laboratory Findings. Red blood cells (RBCs), hemoglobin, platelets, and white blood cells (WBCs)_including basophils, eosinophils, and monocytes - did not significantly differ between the two groups on PODs 2 and 5 (Table 4). Meanwhile, the serum concentrations of CRP, IL-6, and IL10 were comparable between the two groups at all time points (Table4).

3.5. Postoperative Safety Data. There were no significant differences in the incidence of adverse events between groups (Table 2). Bradycardia was noted in one patient (who was in the dexmedetomidine group) after pressing one bolus of PCIA on the operative day, and this issue was resolved after the infusions of PCIA and dexmedetomidine were stopped. No hemodynamic instability was observed after adjusting postoperative analgesia to half the concentration of PCIA and dexmedetomidine. Ultimately, this patient was excluded from this trial.

\section{Discussion}

Our present study represents the first in-depth and systematic evaluation of the effects of perioperative use (i.v. dexmedetomidine) on postoperative analgesia, postoperative recovery, and cellular/inflammatory components of the immune system after surgery. However, dexmedetomidine failed to decrease postoperative opioid consumption, relieve postoperative pain, attenuate inflammation, lessen changes in blood cell counts, reduce the incidence of postoperative complications, accelerate postoperative short-term recovery, decrease the incidence of chronic postsurgical pain, or improve quality of life after discharge.
Our present results contradict the observations of three published studies that also investigated the efficacy of systemic dexmedetomidine in thoracotomy surgery [17, 18, 29]. These trials reported significant effects of postoperative i.v. dexmedetomidine on pain intensity $[18,29]$ and a reduction in opioid consumption $[17,18,29]$. Several nonthoracotomy studies-including hysterectomy [19, 30, 31], inpatient surgery [32], spinal surgery [33], neurosurgery [34], radical mastectomy [35], and open gastrectomy [36] - have also demonstrated significant analgesic effects of dexmedetomidine. The findings of our present study are also in contrast with several meta-analyses that exhibited significant analgesic and opioid-sparing effects for the perioperative administration of systemic dexmedetomidine [12, 37-39]. Of note, these previous meta-analyses included patients undergoing different surgical procedures, so these data on the analgesic efficacies of dexmedetomidine are not directly comparable to the results of our present study. Nevertheless, it may be worthwhile to speculate why our present results, in contrast to those of the above-mentioned trials and metaanalyses, demonstrated that dexmedetomidine had no significant postoperative analgesic effects.

First, the patients underwent lung thoracotomies in one trial $[17,18]$, whereas those undergoing esophageal thoracotomy in the other trial were highly nicotine-dependent patients [29]. Besides that, patients underwent different types of thoracotomy including esophageal neoplasia resection, lobectomy, pneumonectomy, mediastinal mass resection, and pneumothorax [18]. The subjects considerably differed from our present study. All of the patients in our present study underwent complex and extensive surgery for radical esophageal carcinoma via a single incision. Second, the dose with which systemic opioid was infused in our research was higher than that in the three other trials investigating the efficacy of dexmedetomidine in thoracotomy $[17,18,29]$. In our present study, a remifentanil infusion was started after induction of anesthesia and continued until the completion of surgery, whereas remifentanil was not administered in these previous studies. In addition, paravertebral regional block was provided in one previous trial 
TABLE 2: Intraoperative and postoperative data.

\begin{tabular}{|c|c|c|c|c|c|c|c|}
\hline & & & Saline $(n=29)$ & $\begin{array}{l}\text { Dexmedetomidine } \\
\qquad(n=29)\end{array}$ & $p$ value & $\begin{array}{l}\text { Difference between } \\
\text { mean/median }\end{array}$ & $\begin{array}{c}95 \% \\
\text { confidence } \\
\text { interval }\end{array}$ \\
\hline \multirow[t]{11}{*}{$\begin{array}{l}\text { Intraoperative } \\
\text { data }\end{array}$} & $\begin{array}{l}\text { Duration of } \\
\text { surgery }\end{array}$ & $\min$ & $168.72 \pm 50.57$ & $168.62 \pm 61.83$ & 0.994 & $0.103 \pm 14.832$ & $\begin{array}{c}{[-29.609} \\
29.816]\end{array}$ \\
\hline & $\begin{array}{c}\text { Duration of } \\
\text { anesthesia }\end{array}$ & $\min$ & $205.86 \pm 56.58$ & $207.24 \pm 63.02$ & 0.930 & $-1.379 \pm 15.728$ & $\begin{array}{c}{[-32.886,} \\
30.127]\end{array}$ \\
\hline & $\begin{array}{l}\text { Duration of one } \\
\text { lung ventilation }\end{array}$ & $\min$ & $123.21 \pm 75.22$ & $106.38 \pm 71.90$ & 0.388 & $16.828 \pm 19.322$ & $\begin{array}{c}{[-21.879} \\
55.534]\end{array}$ \\
\hline & $\begin{array}{l}\text { Cumulative } \\
\text { propofol dose }\end{array}$ & $\mathrm{mg}$ & $976.92 \pm 434.06$ & $905.17 \pm 397.00$ & 0.514 & $71.745 \pm 109.232$ & $\begin{array}{c}{[-147.073,} \\
290.563]\end{array}$ \\
\hline & $\begin{array}{l}\text { Cumulative } \\
\text { remifentanil dose }\end{array}$ & $\mathrm{mg}$ & $2.48 \pm 1.24$ & $1.66 \pm 1.25$ & $0.015^{*}$ & $0.817 \pm 0.327$ & {$[0.163,1.472]$} \\
\hline & $\begin{array}{c}\text { Cumulative } \\
\text { sufentanil dose }\end{array}$ & $\mu \mathrm{g}$ & $58.52 \pm 10.41$ & $51.12 \pm 9.95$ & $0.008^{*}$ & $7.397 \pm 2.674$ & {$[2.040,12.753]$} \\
\hline & Atropine & $\mathrm{mg}$ & $0.052 \pm 0.14$ & $0.028 \pm 0.08$ & 0.341 & $0.024 \pm 0.03$ & $\begin{array}{c}{[-0.037} \\
0.085]\end{array}$ \\
\hline & Phenylephrine & $\mu \mathrm{g}$ & $46.02 \pm 95.21$ & $52.41 \pm 77.72$ & 0.787 & $-6.207 \pm 22.905$ & $\begin{array}{c}{[-52.092} \\
39.678]\end{array}$ \\
\hline & $\begin{array}{l}\text { Crystalloid } \\
\text { volume }\end{array}$ & $\mathrm{ml}$ & $1379.31 \pm 416.94$ & $1279.31 \pm 352.93$ & 0.328 & $100.000 \pm 101.438$ & $\begin{array}{l}{[-103.204} \\
303.204]\end{array}$ \\
\hline & Colloid volume & $\mathrm{ml}$ & $672.41 \pm 276.32$ & $624.14 \pm 247.35$ & 0.486 & $48.276 \pm 68.867$ & $\begin{array}{c}{[-89.681} \\
186.233]\end{array}$ \\
\hline & Urine volume & $\mathrm{ml}$ & $451.72 \pm 264.40$ & $465.52 \pm 286.95$ & 0.850 & $-13.793 \pm 72.456$ & $\begin{array}{c}{[-158.941,} \\
131.354]\end{array}$ \\
\hline \multirow[t]{4}{*}{ PACU data } & $\begin{array}{l}\text { Time to } \\
\text { awakening }\end{array}$ & $\min$ & $40.83 \pm 31.83$ & $37.03 \pm 17.21$ & 0.575 & $3.793 \pm 6.72$ & $\begin{array}{c}{[-9.668} \\
17.255]\end{array}$ \\
\hline & $\begin{array}{l}\text { Time to } \\
\text { extubation }\end{array}$ & $\min$ & $39.24 \pm 16.75$ & $40.10 \pm 16.83$ & 0.846 & $-0.862 \pm 4.409$ & {$[-9.694,7.97]$} \\
\hline & Time for discharge & $\min$ & $79.38 \pm 33.68$ & $86.86 \pm 42.78$ & 0.462 & $-7.483 \pm 10.11$ & $\begin{array}{c}{[-27.737} \\
12.771]\end{array}$ \\
\hline & $\begin{array}{l}\text { Cumulative } \\
\text { sufentanil dose }\end{array}$ & $\mu \mathrm{g}$ & $1.12 \pm 2.64$ & $1.29 \pm 3.82$ & 0.842 & $-0.172 \pm 0.861$ & $\begin{array}{c}{[-1.898} \\
1.553]\end{array}$ \\
\hline \multirow[t]{13}{*}{$\begin{array}{l}\text { Postoperative } \\
\text { data }\end{array}$} & VAS for pain & & & & & & \\
\hline & POD1 at rest & & $2[2-3]$ & $2[1-3]$ & 0.066 & $-0.414 \pm 0.22$ & $\begin{array}{c}{[-0.855} \\
0.028]\end{array}$ \\
\hline & POD2 at rest & & $2[1-2]$ & $2[1-2]$ & 0.374 & $-0.172 \pm 0.192$ & $\begin{array}{c}{[-0.558} \\
0.213]\end{array}$ \\
\hline & POD5 at rest & & $1[1-1.5]$ & $1[1-1]$ & 0.372 & $-0.138 \pm 0.153$ & $\begin{array}{c}{[-0.445} \\
0.169]\end{array}$ \\
\hline & $\begin{array}{l}\text { POD1 on } \\
\text { movement }\end{array}$ & & $4.77 \pm 1.30$ & $4.79 \pm 1.37$ & 0.922 & $-0.345 \pm 0.351$ & $\begin{array}{c}{[-0.738} \\
0.669]\end{array}$ \\
\hline & $\begin{array}{l}\text { POD2 on } \\
\text { movement }\end{array}$ & & $3.79 \pm 1.01$ & $3.76 \pm 1.15$ & 0.904 & $0.034 \pm 0.285$ & $\begin{array}{c}{[-0.537} \\
0.606]\end{array}$ \\
\hline & $\begin{array}{l}\text { POD5 on } \\
\text { movement }\end{array}$ & & $3[2-4]$ & $3[2-4]$ & 0.467 & $-0.241 \pm 0.329$ & $\begin{array}{c}{[-0.899} \\
0.417]\end{array}$ \\
\hline & $\begin{array}{c}\text { Pressing number of } \\
\text { PCIA-boli }\end{array}$ & & & & & & \\
\hline & $\begin{array}{l}\text { The first } 72 \\
\text { postoperative } h\end{array}$ & & $12.14 \pm 4.76$ & $10.89 \pm 4.66$ & 0.317 & $-1.25 \pm 1.229$ & $\begin{array}{c}{[-3.728} \\
1.228]\end{array}$ \\
\hline & $\begin{array}{c}\text { Total pressing } \\
\text { number of PCIA- } \\
\text { boli } \\
\text { Surgical recovery } \\
\text { scale }\end{array}$ & & $15.03 \pm 14.15$ & $16.97 \pm 11.63$ & 0.572 & $-1.931 \pm 3.401$ & $\begin{array}{c}{[-8.745} \\
4.883]\end{array}$ \\
\hline & POD2 & & $32.86 \pm 2.49$ & $32.97 \pm 1.78$ & 0.856 & $0.11 \pm 0.568$ & $\begin{array}{c}{[-1.029} \\
1.249]\end{array}$ \\
\hline & $\begin{array}{c}\text { POD5 } \\
\text { Sleep quality }\end{array}$ & & $35.69 \pm 2.95$ & $36.00 \pm 2.65$ & 0.675 & $0.31 \pm 0.736$ & {$[-1.165,1.785]$} \\
\hline & POD2 & & $4.00[4.00-4.00]$ & $4.50[4.00-5.00]$ & $0.004^{*}$ & $0.621 \pm 0.211$ & {$[0.198,1.043]$} \\
\hline
\end{tabular}


TABLE 2: Continued.

\begin{tabular}{|c|c|c|c|c|c|c|}
\hline & & Saline $(n=29)$ & $\begin{array}{l}\text { Dexmedetomidine } \\
\quad(n=29)\end{array}$ & $p$ value & $\begin{array}{l}\text { Difference between } \\
\text { mean/median }\end{array}$ & $\begin{array}{c}95 \% \\
\text { confidence } \\
\text { interval }\end{array}$ \\
\hline $\begin{array}{c}\text { POD5 } \\
\text { Clear-headed after } \\
\text { getting up }\end{array}$ & & $4.00[3.00-4.00]$ & $4.00[4.00-5.00]$ & $0.008^{*}$ & $0.759 \pm 0.265$ & {$[0.228,1.290]$} \\
\hline POD2 & & $3.00[3.00-4.00]$ & $4.00[3.00-4.50]$ & 0.1102 & $0.379 \pm 0.234$ & $\begin{array}{c}{[-0.088} \\
0.847]\end{array}$ \\
\hline $\begin{array}{c}\text { POD5 } \\
\text { Sleep satisfaction }\end{array}$ & & $3.00[3.00-4.00]$ & $4.00[3.00-5.00]$ & $0.0026^{*}$ & $0.724 \pm 0.230$ & {$[0.264,1.184]$} \\
\hline POD2 & & $3.00[3.00-4.00]$ & $3.00[3.00-4.00]$ & 0.858 & $-0.034 \pm 0.192$ & $\begin{array}{c}{[-0.418} \\
0.349]\end{array}$ \\
\hline POD5 & & $3.00[3.00-4.00]$ & $4.00[3.00-4.00]$ & 0.058 & $0.414 \pm 0.214$ & $\begin{array}{c}{[-0.014} \\
0.842]\end{array}$ \\
\hline PONV & $n(\%)$ & $3(10.3)$ & $2(6.9)$ & 0.640 & & \\
\hline Adverse events & $n(\%)$ & $8(27.59)$ & $3(10.34)$ & 0.179 & & \\
\hline Pleural effusion & & 3 & 2 & & & \\
\hline Pneumonia & & 1 & 0 & & & \\
\hline $\begin{array}{l}\text { Anastomotic } \\
\text { fistula }\end{array}$ & & 1 & 0 & & & \\
\hline $\begin{array}{l}\text { Poor intestinal } \\
\text { peristalsis }\end{array}$ & & 1 & 0 & & & \\
\hline Delirium & & 1 & 0 & & & \\
\hline Transfusion & & 1 & 1 & & & \\
\hline $\begin{array}{l}\text { First out-of-bed } \\
\text { activity }\end{array}$ & days & $3.21 \pm 0.98$ & $3.54 \pm 1.26$ & 0.275 & $-0.329 \pm 0.298$ & $\begin{array}{c}{[-0.927} \\
0.269]\end{array}$ \\
\hline $\begin{array}{l}\text { Removal of chest } \\
\text { drainage tube }\end{array}$ & days & $9.55 \pm 1.96$ & $9.54 \pm 2.19$ & 0.977 & $0.016 \pm 0.549$ & {$[-1.084,1.116]$} \\
\hline $\begin{array}{c}\text { First intestinal } \\
\text { aerofluxus }\end{array}$ & days & $5.14 \pm 3.79$ & $4.61 \pm 1.52$ & 0.493 & $0.531 \pm 0.77$ & {$[-1.012,2.073]$} \\
\hline Time for discharge & days & $23.69 \pm 7.59$ & $22.34 \pm 3.67$ & 0.394 & $1.345 \pm 1.566$ & {$[-1.792,4.481]$} \\
\hline $\begin{array}{c}\text { Time for } \\
\text { postoperative } \\
\text { hospital stay }\end{array}$ & days & $14.48 \pm 7.06$ & $12.38 \pm 2.50$ & 0.136 & $2.103 \pm 1.391$ & $\begin{array}{c}{[-0.684} \\
4.891]\end{array}$ \\
\hline Hospital cost & $\mathrm{CNY}$ & $50,878.03 \pm 12061.19$ & $48,808.29 \pm 9510.67$ & 0.471 & $2069.75 \pm 2852.254$ & $\begin{array}{c}{[-3644.001} \\
7783.5]\end{array}$ \\
\hline
\end{tabular}

Data are shown as absolute numbers $(n)$, percentages of the total population $(N)$, and the mean \pm standard error or median (interquartile range), as appropriate. POD: postoperative day; PACU: postanesthesia care unit; VAS: visual analog scale; PCIA: patient-controlled i.v. analgesia; PONV: postoperative nausea and vomiting; CNY: China Yuan.

TABLE 3: Long-term recovery data.

\begin{tabular}{lcccccc}
\hline & $\begin{array}{c}\text { Saline } \\
(n=28)\end{array}$ & $\begin{array}{c}\text { Dexmedetomidine } \\
(n=28)\end{array}$ & p value & $\begin{array}{c}\text { Difference between mean/ } \\
\text { median }\end{array}$ & $\begin{array}{c}95 \% \text { confidence } \\
\text { interval }\end{array}$ \\
\hline $\begin{array}{l}\text { SF- } \\
8\end{array}$ & Baseline & $13.10 \pm 3.65$ & $12.07 \pm 2.88$ & 0.236 & $1.034 \pm 0.863$ & {$[-0.694,2.763]$} \\
\hline $\begin{array}{c}1 \text { month after } \\
\text { surgery }\end{array}$ & $27.10 \pm 5.90$ & $27.72 \pm 3.50$ & 0.628 & $-0.621 \pm 1.274$ & {$[-3.173,1.932]$} \\
3 months after & $22.90 \pm 6.17$ & $24.62 \pm 5.52$ & 0.267 & $-1.724 \pm 1.537$ & {$[-4.803,1.354]$} \\
\hline
\end{tabular}

Data are reported as the mean \pm standard error as appropriate. SF: short-form.

[17], while our patients just received $0.1-0.2 \mu \mathrm{g} / \mathrm{kg}$ sufentanil at the end of thoracotomies without neural blockade. Moreover, PCIA with continuously infused sufentanil $(0.06 \mu \mathrm{g} / \mathrm{kg} / \mathrm{h})$ was higher than that in the other three trials; analgesic effects of dexmedetomidine may have been masked by the perioperative use of opioids. Third, flurbiprofen axetil, a nonsteroidal anti-inflammatory drug perioperatively administrated in our present study, plays an essential part of analgesia in multimodal analgesia [40-42]. Likewise, postoperative analgesic effects of dexmedetomidine may be hidden when flurbiprofen axetil is infused perioperatively. Fourth, the dose with which postoperative i.v. 
TABLE 4: Laboratory data.

\begin{tabular}{|c|c|c|c|c|c|c|c|}
\hline & & & Saline $(n=29)$ & $\begin{array}{l}\text { Dexmedetomidine } \\
(n=29)\end{array}$ & $\begin{array}{c}p \\
\text { value }\end{array}$ & $\begin{array}{l}\text { Difference between mean/ } \\
\text { median }\end{array}$ & $\begin{array}{l}95 \% \text { confidence } \\
\text { interval }\end{array}$ \\
\hline \multirow[t]{28}{*}{$\begin{array}{l}\text { Blood cell } \\
\text { count }\end{array}$} & Red blood cell & $10^{12} / \mathrm{L}$ & & & & & \\
\hline & Baseline & & $4.37 \pm 0.50$ & $4.38 \pm 0.52$ & 0.941 & $0.01 \pm 0.134$ & {$[-0.258,0.27]$} \\
\hline & POD2 & & $3.70 \pm 0.57$ & $3.71 \pm 0.54$ & 0.946 & $0.01 \pm 0.146$ & {$[-0.282,0.302]$} \\
\hline & POD5 & & $3.56 \pm 0.57$ & $3.58 \pm 0.62$ & 0.900 & $0.02 \pm 0.156$ & {$[-0.293,0.333]$} \\
\hline & Hemoglobin & $\mathrm{g} / \mathrm{L}$ & & & & & \\
\hline & Baseline & & $131.59 \pm 11.56$ & $130.21 \pm 16.10$ & 0.709 & $-1.380 \pm 3.681$ & {$[-8.753,5.993]$} \\
\hline & POD2 & & $111.61 \pm 14.62$ & $109.12 \pm 14.54$ & 0.518 & $-2.490 \pm 3.829$ & {$[-10.16,5.18]$} \\
\hline & POD5 & & $106.21 \pm 15.09$ & $105.28 \pm 16.97$ & 0.826 & $-0.93 \pm 4.217$ & {$[-9.377,7.517]$} \\
\hline & $\begin{array}{c}\text { White blood } \\
\text { cell }\end{array}$ & $10^{9} / \mathrm{L}$ & & & & & \\
\hline & Baseline & & $5.69 \pm 1.62$ & $5.64 \pm 1.51$ & 0.911 & $-0.05 \pm 0.411$ & {$[-8.378,0.774]$} \\
\hline & POD2 & & $11.03 \pm 3.42$ & $10.10 \pm 3.44$ & 0.314 & $-0.93 \pm 0.901$ & {$[-2.734,0.875]$} \\
\hline & POD5 & & $7.63 \pm 2.61$ & $7.86 \pm 3.67$ & 0.792 & $0.23 \pm 0.836$ & {$[-1.445,1.905]$} \\
\hline & Basophils & $10^{9} / \mathrm{L}$ & & & & & \\
\hline & Baseline & & $0.21 \pm 0.93$ & $0.05 \pm 0.13$ & 0.363 & $-0.16 \pm 0.174$ & {$[-0.509,0.189]$} \\
\hline & POD2 & & $0.01 \pm 0.007$ & $0.008 \pm 0.006$ & 0.281 & $-0.002 \pm 0.002$ & {$[-0.007,0.002]$} \\
\hline & POD5 & & $0.03 \pm 0.56$ & $0.04 \pm 0.12$ & 0.925 & $0.01 \pm 0.106$ & {$[-0.203,0.223]$} \\
\hline & Eosinophil & $10^{9} / \mathrm{L}$ & & & & & \\
\hline & Baseline & & $0.85 \pm 2.13$ & $0.16 \pm 0.12$ & 0.090 & $-0.690 \pm 0.396$ & {$[-1.484,0.396]$} \\
\hline & POD2 & & $0.34 \pm 1.32$ & $0.30 \pm 1.31$ & 0.908 & $-0.04 \pm 0.345$ & {$[-0.732,0.652]$} \\
\hline & POD5 & & $0.21 \pm 0.16$ & $0.17 \pm 0.13$ & 0.301 & $-0.04 \pm 0.038$ & {$[-0.117,0.037]$} \\
\hline & Monocyte & $10^{9} / \mathrm{L}$ & & & & & \\
\hline & Baseline & & $0.42 \pm 0.19$ & $0.37 \pm 0.16$ & 0.283 & $-0.05 \pm 0.046$ & {$[-0.142,0.042]$} \\
\hline & POD2 & & $0.57 \pm 0.23$ & $0.56 \pm 0.24$ & 0.872 & $-0.01 \pm 0.062$ & {$[-0.134,0.114]$} \\
\hline & POD5 & & $0.57 \pm 0.27$ & $0.55 \pm 0.28$ & 0.783 & $-0.02 \pm 0.072$ & {$[-0.165,0.125]$} \\
\hline & Platelet & $10^{9} / \mathrm{L}$ & & & & & \\
\hline & Baseline & & $212.83 \pm 68.14$ & $196.72 \pm 64.80$ & 0.360 & $-16.11 \pm 17.46$ & {$[-51.09,18.87]$} \\
\hline & POD2 & & $143.79 \pm 40.62$ & $153.64 \pm 71.22$ & 0.527 & $9.85 \pm 15.23$ & {$[-20.65,40.35]$} \\
\hline & POD5 & & $199.59 \pm 62.86$ & $192.48 \pm 73.08$ & 0.639 & $-7.11 \pm 17.9$ & {$[-42.97,28.75]$} \\
\hline \multirow[t]{15}{*}{ Cytokines } & $C R P$ & $\mu \mathrm{g} / \mathrm{ml}$ & & & & & \\
\hline & Baseline & & $2.29 \pm 1.27$ & $2.23 \pm 1.71$ & 0.88 & $-0.06 \pm 0.396$ & {$[-0.852,0.7324]$} \\
\hline & End of surgery & & $1.47 \pm 1.31$ & $1.57 \pm 1.63$ & 0.80 & $0.1 \pm 0.388$ & {$[-0.678,0.878]$} \\
\hline & POD2 & & $5.03 \pm 0.59$ & $5.21 \pm 1.26$ & 0.489 & $0.18 \pm 0.258$ & {$[-0.338,0.7]$} \\
\hline & POD5 & & $4.80 \pm 1.81$ & $5.08 \pm 1.51$ & 0.525 & $0.28 \pm 0.438$ & {$[-0.6,1.157]$} \\
\hline & $I L-6$ & $\mathrm{pg} / \mathrm{ml}$ & & & & & \\
\hline & Baseline & & $13.74 \pm 8.63$ & $11.19 \pm 3.22$ & 0.628 & $-2.55 \pm 1.71$ & {$[-5.976,0.877]$} \\
\hline & End of surgery & & $14.88 \pm 6.36$ & $17.27 \pm 7.23$ & 0.708 & $2.390 \pm 1.788$ & {$[-1.192,5.972]$} \\
\hline & POD2 & & $15.91 \pm 10.41$ & $19.08 \pm 8.11$ & 0.59 & $3.17 \pm .45$ & {$[-1.739,8.079]$} \\
\hline & POD5 & & $9.33 \pm 4.18$ & $14.22 \pm 8.64$ & 0.140 & $2.890 \pm 1.782$ & {$[-0.68,6.46]$} \\
\hline & $I L-10$ & $\mathrm{pg} / \mathrm{ml}$ & & & & & \\
\hline & Baseline & & $15.79 \pm 8.74$ & $12.76 \pm 7.88$ & 0.674 & $-3.03 \pm 2.185$ & {$[-7.408,1.348]$} \\
\hline & End of surgery & & $23.70 \pm 10.71$ & $19.92 \pm 11.02$ & 0.191 & $-3.78 \pm 2.854$ & [-9.496 to 1.936$]$ \\
\hline & POD2 & & $14.51 \pm 6.94$ & $19.39 \pm 8.46$ & 0.393 & $4.88 \pm 2.032$ & {$[-10.95,1.182]$} \\
\hline & POD5 & & $14.92 \pm 10.81$ & $12.85 \pm 8.12$ & 0.928 & $-2.07 \pm 2.511$ & {$[-3.998,8.137]$} \\
\hline
\end{tabular}

Data are reported as the mean \pm standard error as appropriate. POD: postoperative day.

dexmedetomidine was infused in our trial $(0.06 \mu \mathrm{g} / \mathrm{kg} / \mathrm{h})$ was lower than that in one trial researching the efficacy of dexmedetomidine titrated from 0.1 to $0.5 \mu \mathrm{g} / \mathrm{kg} / \mathrm{h}$ after surgery for up to $24 \mathrm{~h}$ in thoracotomy [17]. In our present study, a bolus was given before induction of anesthesia, and the infusion of dexmedetomidine was continued until POD 5. This likely resulted in a higher cumulative dexmedetomidine dose when compared with that of a previous study [17]. Moreover, our dose of the dexmedetomidine infusion was higher than that used in the other two studies $[18,29]$. Therefore, the failure of dexmedetomidine to reduce postoperative opioid requirements cannot be attributed to underdosing.

It has been reported that intraoperative dexmedetomidine administration is beneficial for the recovery of gastrointestinal motility function after resection of colorectal cancer, with stable hemodynamics during surgery [43]. In lower gastrointestinal surgery, postoperative ileus is mainly attributed to both inflammation and direct injury to gastrointestinal tissue. Dexmedetomidine counteracts both of these mechanisms by protection against intestinal epithelial barrier disruption [44] and inhibiting the inflammatory response [45]. In contrast, 
thoracotomy for esophageal cancer does not trigger postoperative ileus by direct injury to the intestines or manipulation/distraction of the plexuses of splanchnic nerves, which are located anterior to the lumbar column [40]. Consequently, we did not observe a significant reduction in the time to recovery of intestinal function in our present study.

Cytokines and immune cells are crucially important in several mechanisms underlying pain [46, 47] and postoperative recovery [48, 49]. Proinflammatory cytokines and anti-inflammatory cytokines are involved in modulating pain sensitivity and, conversely, can also be influenced in synthesis and release during pain stimuli [50]. Dexmedetomidine has anti-inflammatory effects by attenuating the plasma levels of proinflammatory cytokines [51-53]. Thoracotomy for esophageal cancer is not only associated with severe postoperative pain but also provokes a tremendous systemic inflammatory response [54]. The inflammatory reaction significantly affects postoperative recovery, as excessive stimulation of the inflammatory cascade can predict the outcome after surgery and lead to infection, pain, systemic inflammatory response syndrome, and organ dysfunction $[47,55]$. However, dexmedetomidine failed to exert anti-inflammatory or analgesic effects in our patients.

Our findings indicate that perioperative use of dexmedetomidine reduced intraoperative opioid consumption and improved postoperative sleep quality in patients undergoing lateral thoracotomy for thoracic esophageal cancer. These results are in accordance with the results of previous trials [56-59], in which dexmedetomidine decreased opioid consumption during intraoperative infusion and improved sleep quality during postoperative administration.

Chronic pain remains a challenge in pain control after thoracic surgery, and the incidence of chronic postsurgical pain increases when acute postoperative pain is not adequately controlled [3]. Jain et al. [60] found a benefit of dexmedetomidine on the incidence and severity of chronic pain at 3 months after breast cancer surgery; however, few studies have focused on chronic pain after thoracotomy with perioperative administration of dexmedetomidine. In our present study, the incidence of chronic pain $(21 \%$ in the saline group and $20 \%$ in the dexmedetomidine group) remained low compared with the incidences reported in the literature $[61,62]$. These results may be attributed to multimodal analgesia with opioid and flurbiprofen axetil associated with the application of PCIA.

Our present study had several limitations. First, it is debatable whether the VAS for pain is an adequate tool for evaluating the effects of dexmedetomidine on pain control. Hence, further establishment of whether VAS for pain is an adequate tool for dexmedetomidine to evaluate pain control is needed in future studies. The VAS is significantly influenced by the dosage of opioids that are administered. However, postoperative pain medication, including sufentanil and flurbiprofen axetil, was standardized in our present study and no significant difference was found in the analgesic requirements between the two groups. A second limitation of our present study is that we did not measure the dexmedetomidine concentrations in our patients. However, the dose of dexmedetomidine treatment used in our study has been shown to be effective and safe in other clinical trials [17, 18, 29]. Third, the sample size estimation in our study was based on the postoperative opioid-sparing effect of dexmedetomidine, which was powered solely as the primary endpoint in our present study. It cannot be excluded that statistically significant differences in secondary outcomes may have become apparent after the inclusion of a larger sample size. Fourth, the infusion of dexmedetomidine during anesthesia causes increasing in blood pressure and reduction of heart rate within acceptable range, which is difficult for the anesthesiologist to be blind. However, the stuff to follow-up were not the intraoperative anesthesiologists, which minimizes bias. Fifth, the practice of intraoperative administration of remifentanil for analgesia is highly debated. Remifentanil is reportedly associated with tolerance and hyperalgesia during the postoperative period [63]; however, its use was required in our present study to allow early extubation in the majority of patients.

It is noteworthy that the optimal dosing titration frequency and dosage of dexmedetomidine that balance safety and efficacy for postoperative analgesia are currently unknown. In our present study, the dosage of postoperative dexmedetomidine was $0.06 \mu \mathrm{g} / \mathrm{kg} / \mathrm{h}$, although one study reported a higher dosage [18]. In our present study, only one patient experienced bradycardia, which resolved after the infusions of PCIA and dexmedetomidine were terminated. Other patients were not influenced by bradycardia, but our sample size may not have been large enough to detect such a change. Therefore, further studies are needed to determine the optimal dosage of postoperative dexmedetomidine in lateral thoracotomy for esophageal cancer with a lower incidence of hypotension and bradycardia.

\section{Conclusions}

In conclusion, the results of our present study indicate that perioperative use of systemic dexmedetomidine can decrease intraoperative opioid consumption and improve postoperative sleep quality; furthermore, this dexmedetomidine treatment had no effect on postoperative analgesia, the immune system, or short- or long-term recovery when added to opioid-based multimodal analgesia. These findings provide new evidence that adding dexmedetomidine may only provide limited benefit in thoracotomy surgery when acute pain is controlled with conventional multimodal analgesia. Further research should focus not only on the optional dosage of perioperatively administrated dexmedetomidine but also on clear identification of the effect of dexmedetomidine on the immune system and the putative mechanism of its analgesic action.

\section{Data Availability}

The data used to support the findings of this study are available from the corresponding author upon request. 


\section{Conflicts of Interest}

The authors declare that there are no conflicts of interest regarding the publication of this paper.

\section{Authors' Contributions}

Yu Mao and Xuemei Sun contributed equally to this study. All authors contributed to study design/planning and revised the paper. Yu Mao and Xuemei Sun contributed to study conduct and writing the paper. Yu Mao, Li Si, and Lijian Chen contributed to data analysis.

\section{Acknowledgments}

The authors would like to express their appreciation to Xiaohu Zheng for his invaluable assistance. This paper was supported by Youth Incubation Fund of the First Affiliated Hospital of Anhui Medical University.

\section{References}

[1] C. P. Fagundes, Q. Shi, A. A. Vaporciyan et al., "Symptom recovery after thoracic surgery: measuring patient-reported outcomes with the MD Anderson Symptom Inventory," The Journal of Thoracic and Cardiovascular Surgery, vol. 150, no. 3, pp. 613-619, 2015.

[2] A. Mesbah, J. Yeung, and F. Gao, "Pain after thoracotomy," BJA Education, vol. 16, no. 1, pp. 1-7, 2016.

[3] P. Gerner, "Postthoracotomy pain management problems," Anesthesiology Clinics, vol. 26, no. 2, pp. 355-367, 2008.

[4] R. Hughes and F. Gao, "Pain control for thoracotomy," Continuing Education in Anaesthesia Critical Care \& Pain, vol. 5, no. 2, pp. 56-60, 2005.

[5] K. McGreevy, M. M. Bottros, and S. N. Raja, "Preventing chronic pain following acute pain: risk factors, preventive strategies, and their efficacy," European Journal of Pain Supplements, vol. 5, no. 2, pp. 365-372, 2011.

[6] A. Schnabel and E. Pogatzki-Zahn, "Predictors of chronic pain following surgery. What do we know?" Der Schmerz, vol. 24, no. 5, pp. 517-533, 2010.

[7] K. Wildgaard, J. Ravn, and H. Kehlet, "Chronic post-thoracotomy pain: a critical review of pathogenic mechanisms and strategies for prevention," European Journal of Cardio-Thoracic Surgery, vol. 36, no. 1, pp. 170-180, 2009.

[8] R. Benyamin, A. M. Trescot, S. Datta et al., "Opioid complications and side effects," Pain Physician, vol. 11, no. 2, pp. S105-S120, 2008.

[9] M. Wheeler, G. M. Oderda, M. A. Ashburn, and A. G. Lipman, "Adverse events associated with postoperative opioid analgesia: a systematic review," The Journal of Pain, vol. 3, no. 3, pp. 159-180, 2002.

[10] M. Wenk and S. A. Schug, "Perioperative pain management after thoracotomy," Current Opinion in Anaesthesiology, vol. 24, no. 1, pp. 8-12, 2011.

[11] M. Kaur and P. Singh, "Current role of dexmedetomidine in clinical anesthesia and intensive care," Anesthesia: Essays and Researches, vol. 5, no. 2, pp. 128-133, 2011.

[12] K. Peng, H.-Y. Liu, S.-R. Wu, H. Cheng, and F.-H. Ji, "Effects of combining dexmedetomidine and opioids for postoperative intravenous patient-controlled analgesia: a systematic review and meta-analysis," The Clinical Journal of Pain, vol. 31, no. 12, pp. 1097-1104, 2015.
[13] R. Gertler, H. C. Brown, D. H. Mitchell, and E. N. Silvius, "Dexmedetomidine: a novel sedative-analgesic agent," Baylor University Medical Center Proceedings, vol. 14, no. 1, pp. 13-21, 2001.

[14] X. Li, J. Yang, X.-L. Nie et al., "Impact of dexmedetomidine on the incidence of delirium in elderly patients after cardiac surgery: a randomized controlled trial," PLoS One, vol. 12, no. 2, Article ID e0170757, 2017.

[15] S. Deiner, X. Luo, H. Lin et al., "Intraoperative infusion of dexmedetomidine for prevention of postoperative delirium and cognitive dysfunction in elderly patients undergoing major elective noncardiac surgery: a randomized clinical trial," JAMA Surgery, vol. 152, no. 8, Article ID e171505, 2017.

[16] X. Su, Z.-T. Meng, X.-H. Wu et al., "Dexmedetomidine for prevention of delirium in elderly patients after non-cardiac surgery: a randomised, double-blind, placebo-controlled trial," The Lancet, vol. 388, no. 10054, pp. 1893-1902, 2016.

[17] M. A. E. Ramsay, K. B. Newman, B. Leeper et al., "Dexmedetomidine infusion for analgesia up to 48 hours after lung surgery performed by lateral thoracotomy," Baylor University Medical Center Proceedings, vol. 27, no. 1, pp. 3-10, 2014.

[18] C.-S. Dong, J. Zhang, Q. Lu et al., "Effect of dexmedetomidine combined with sufentanil for post- thoracotomy intravenous analgesia:a randomized, controlled clinical study," $B M C$ Anesthesiology, vol. 17, no. 1, p. 33, 2017.

[19] C. Ren, M. Chi, Y. Zhang, Z. Zhang, F. Qi, and Z. Liu, "Dexmedetomidine in postoperative analgesia in patients undergoing hysterectomy: a CONSORT-prospective, randomized, controlled trial," Medicine, vol. 94, no. 32, Article ID e1348, 2015.

[20] A. R. Absalom, V. Mani, T. De Smet, and M. M. R. F. Struys, "Pharmacokinetic models for propofol-defining and illuminating the devil in the detail," British Journal of Anaesthesia, vol. 103, no. 1, pp. 26-37, 2009.

[21] Z. Al-Rifai and D. Mulvey, "Principles of total intravenous anaesthesia: basic pharmacokinetics and model descriptions," BJA Education, vol. 16, no. 3, pp. 92-97, 2016.

[22] B. W. Ellis, M. W. Johns, R. Lancaster, P. Raptopoulos, N. Angelopoulos, and R. G. Priest, "The St. Mary's Hospital sleep questionnaire: a study of reliability," Sleep, vol. 4, no. 1, pp. 93-97, 1981.

[23] J. S. Paddison, T. Sammour, A. Kahokehr, K. ZargarShoshtari, and A. G. Hill, "Development and validation of the surgical recovery scale (SRS)," Journal of Surgical Research, vol. 167, no. 2, pp. e85-e91, 2011.

[24] Y. Tokuda, T. Okubo, S. Ohde et al., "Assessing items on the SF-8 Japanese version for health-related quality of life: a psychometric analysis based on the nominal categories model of item response theory," Value in Health, vol. 12, no. 4, pp. $568-573,2009$.

[25] D. M. Turner-Bowker, M. S. Bayliss, J. E. Ware Jr., and M. Kosinski, "Usefulness of the SF-8 health survey for comparing the impact of migraine and other conditions," Quality of Life Research: An International Journal of Quality of Life Aspects of Treatment, Care and Rehabilitation, vol. 12, no. 8, pp. 1003-1012, 2003.

[26] Y. Mao, Y. Zuo, B. Mei et al., "Efficacy of perineural dexamethasone with ropivacaine in thoracic paravertebral block for postoperative analgesia in elective thoracotomy: a randomized, double-blind, placebo-controlled trial," Journal of Pain Research, vol. 11, pp. 1811-1819, 2018.

[27] D. Moher, S. Hopewell, K. F. Schulz et al., "CONSORT 2010 explanation and elaboration: updated guidelines for reporting 
parallel group randomised trials," International Journal of Surgery, vol. 10, no. 1, pp. 28-55, 2012.

[28] K. F. Schulz, D. G. Altman, D. Moher, and CONSORT Group, "CONSORT 2010 statement: updated guidelines for reporting parallel group randomised trials," International Journal of Surgery, vol. 9, no. 8, pp. 672-677, 2011.

[29] C. Ren, X. Zhang, Z. Liu, C. Li, Z. Zhang, and F. Qi, "Effect of intraoperative and postoperative infusion of dexmedetomidine on the quality of postoperative analgesia in highly nicotine-dependent patients after thoracic surgery: a CONSORT-prospective, randomized, controlled Trial," Medicine, vol. 94, no. 32, Article ID e1348, 2015.

[30] A. Gurbet, E. Basagan-Mogol, G. Turker, F. Ugun, F. N. Kaya, and B. Ozcan, "Intraoperative infusion of dexmedetomidine reduces perioperative analgesic requirements," Canadian Journal of Anesthesia/Journal Canadien D'anesthésie, vol. 53, no. 7, pp. 646-652, 2006.

[31] T.-F. Lin, Y.-C. Yeh, F.-S. Lin et al., "Effect of combining dexmedetomidine and morphine for intravenous patientcontrolled analgesia," British Journal of Anaesthesia, vol. 102, no. 1, pp. 117-122, 2009.

[32] S. R. Arain, R. E. M. Ruehlow, T. D. Uhrich, and T. J. Ebert, "The efficacy of dexmedetomidine versus morphine for postoperative analgesia after major inpatient surgery," $A n$ esthesia \& Analgesia, vol. 98, no. 1, pp. 153-158, 2004.

[33] C.-S. Dong, Y. Lu, J. Zhang et al., "The optimal dose of dexmedetomidine added to an sufentanil-based analgesic regimen for postoperative pain control in spine surgery: a probit analysis study," Medicine, vol. 95, no. 39, Article ID e4776, 2016.

[34] S. Su, C. Ren, H. Zhang, Z. Liu, and Z. Zhang, "The opioidsparing effect of perioperative dexmedetomidine plus sufentanil infusion during neurosurgery: a retrospective study," Frontiers in Pharmacology, vol. 7, no. 407, 2016.

[35] W. Fan, H. Xue, Y. Sun et al., "Dexmedetomidine improves postoperative patient-controlled analgesia following radical mastectomy," Frontiers in Pharmacology, vol. 8, no. 250, 2017.

[36] N. Y. Kim, T. D. Kwon, S. J. Bai et al., "Effects of dexmedetomidine in combination with fentanyl-based intravenous patient-controlled analgesia on pain attenuation after open gastrectomy in comparison with conventional thoracic epidural and fentanyl-based intravenous patient-controlled analgesia," International Journal of Medical Sciences, vol. 14, no. 10, pp. 951-960, 2017.

[37] G. Blaudszun, C. Lysakowski, N. Elia, and M. R. Tramèr, "Effect of perioperative systemic $\alpha_{2}$ agonists on postoperative morphine consumption and pain intensity: systematic review and meta-analysis of randomized controlled Trials," Anesthesiology, vol. 116, no. 6, pp. 1312-1322, 2012.

[38] N. H. Waldron, C. A. Jones, T. J. Gan, T. K. Allen, and A. S. Habib, "Impact of perioperative dexamethasone on postoperative analgesia and side-effects: systematic review and meta-analysis," British Journal of Anaesthesia, vol. 110, no. 2, pp. 191-200, 2013.

[39] A. Schnabel, C. H. Meyer-Frieem, S. U. Reichl, P. K. Zahn, and E. M. Pogatzki-Zahn, "Is intraoperative dexmedetomidine a new option for postoperative pain treatment? A meta-analysis of randomized controlled trials," Pain, vol. 154, no. 7 , pp. 1140-1149, 2013.

[40] Y. Mao, Y. Cao, B. Mei et al., "Efficacy of Nalbuphine with flurbiprofen on multimodal analgesia with transverse abdominis plane block in elderly patients undergoing open gastrointestinal surgery: a randomized, controlled, double-blinded trial," Pain
Research and Management, vol. 2018, Article ID 3637013, 9 pages, 2018.

[41] X. Lin, R. Zhang, J. Xing, X. Gao, P. Chang, and W. Li, "Flurbiprofen axetil reduces postoperative sufentanil consumption and enhances postoperative analgesic effects in patients with colorectal cancer surgery," International Journal of Clinical and Experimental Medicine, vol. 7, no. 12, pp. 4887-4896, 2014.

[42] J. P. Cata and J. D. Lasala, "Perioperative pain management," in Basic Sciences in Anesthesia, E. Farag, M. Argalious, J. E. Tetzlaff, and D. Sharma, Eds., pp. 515-525, Springer International Publishing, Cham, Switzerland, 2018.

[43] C. Chen, P. Huang, L. Lai et al., "Dexmedetomidine improves gastrointestinal motility after laparoscopic resection of colorectal cancer: a randomized clinical trial," Medicine, vol. 95, no. 29, Article ID e4295, 2016.

[44] Y.-C. Yeh, C.-Y. Wu, Y.-J. Cheng et al., "Effects of dexmedetomidine on intestinal microcirculation and intestinal epithelial barrier in endotoxemic rats," Anesthesiology, vol. 125, no. 2, pp. 355-367, 2016.

[45] Y. Chen, L. Miao, Y. Yao et al., "Dexmedetomidine ameliorate CLP-induced rat intestinal injury via inhibition of inflammation," Mediators of Inflammation, vol. 2015, Article ID 918361, 9 pages, 2015.

[46] J.-M. Zhang and J. An, "Cytokines, inflammation, and pain," International Anesthesiology Clinics, vol. 45, no. 2, pp. 27-37, 2007.

[47] B. Beilin, Y. Shavit, E. Trabekin et al., "The effects of postoperative pain management on immune response to surgery," Anesthesia \& Analgesia, vol. 97, no. 3, pp. 822-827, 2003.

[48] C.-H. Hsing and J.-J. Wang, "Clinical implication of perioperative inflammatory cytokine alteration," Acta Anaesthesiologica Taiwanica, vol. 53, no. 1, pp. 23-28, 2015.

[49] G. S. A. Boersema, Z. Wu, A. G. Menon, G. J. Kleinrensink, J. Jeekel, and J. F. Lange, "Systemic inflammatory cytokines predict the infectious complications but not prolonged postoperative ileus after colorectal surgery," Mediators of Inflammation, vol. 2018, Article ID 7141342, 9 pages, 2018.

[50] C. M. B. D. Oliveira, R. K. Sakata, A. M. Issy, L. R. Gerola, and R. Salomão, "Citocinas e dor," Revista Brasileira de Anestesiologia, vol. 61, no. 2, pp. 260-265, 2011.

[51] H. Xiang, B. Hu, Z. Li, and J. Li, "Dexmedetomidine controls systemic cytokine levels through the cholinergic anti-inflammatory pathway," Inflammation, vol. 37, no. 5, pp. 1763-1770, 2014.

[52] B. Li, Y. Li, S. Tian et al., "Anti-inflammatory effects of perioperative dexmedetomidine administered as an adjunct to general anesthesia: a meta-analysis," Scientific Reports, vol. 5, no. 1, p. 12342, 2015.

[53] S.-H. Kang, Y.-S. Kim, T.-H. Hong et al., "Effects of dexmedetomidine on inflammatory responses in patients undergoing laparoscopic cholecystectomy," Acta Anaesthesiologica Scandinavica, vol. 57, no. 4, pp. 480-487, 2013.

[54] H. Shimada, T. Ochiai, S.-I. Okazumi et al., "Clinical benefits of steroid therapy on surgical stress in patients with esophageal cancer," Surgery, vol. 128, no. 5, pp. 791-798, 2000.

[55] N. B. Jamieson, P. Glen, D. C. McMillan et al., "Systemic inflammatory response predicts outcome in patients undergoing resection for ductal adenocarcinoma head of pancreas," British Journal of Cancer, vol. 92, no. 1, pp. 21-23, 2004.

[56] A. Arcangeli, C. D’Alo, and R. Gaspari, "Dexmedetomidine use in general anaesthesia," Current Drug Targets, vol. 10, no. 8, pp. 687-695, 2009. 
[57] L. A. McQueen-Shadfar, S. A. Megalla, W. D. White, A. J. Olufolabi, C. A. Jones, and A. S. Habib, "Impact of intraoperative dexmedetomidine on postoperative analgesia following gynecologic surgery," Current Medical Research and Opinion, vol. 27, no. 11, pp. 2091-2097, 2011.

[58] Z. Chen, R. Tang, R. Zhang, Y. Jiang, and Y. Liu, "Effects of dexmedetomidine administered for postoperative analgesia on sleep quality in patients undergoing abdominal hysterectomy," Journal of Clinical Anesthesia, vol. 36, pp. 118-122, 2017.

[59] X.-H. Wu, F. Cui, C. Zhang et al., "Low-dose dexmedetomidine improves sleep quality pattern in elderly patients after noncardiac surgery in the intensive care unit: a pilot randomized controlled trial," Anesthesiology, vol. 125, no. 5, pp. 979-991, 2016.

[60] G. Jain, B. Ahmad, G. Yadav, P. Bansal, and D. Singh, "Effect of the perioperative infusion of dexmedetomidine on chronic pain after breast surgery," Indian Journal of Palliative Care, vol. 18, no. 1, pp. 45-51, 2012.

[61] E. O. Bayman and T. J. Brennan, "Incidence and severity of chronic pain at 3 and 6 months after thoracotomy: metaanalysis," The Journal of Pain, vol. 15, no. 9, pp. 887-897, 2014.

[62] H. T. Wang, W. Liu, A. L. Luo, C. Ma, and Y. G. Huang, "Prevalence and risk factors of chronic post-thoracotomy pain in Chinese patients from Peking Union Medical College Hospital," Chinese Medical Journal, vol. 125, no. 17, pp. 3033-3038, 2012.

[63] E. H. Y. Yu, D. H. D. Tran, S. W. Lam, and M. G. Irwin, "Remifentanil tolerance and hyperalgesia: short-term gain, long-term pain?” Anaesthesia, vol. 71, no. 11, pp. 1347-1362, 2016. 